\title{
Effects of Specific Weight Exercises on Improving the Attack and Opponent Control Levels during Group Play for Judokas
}

\section{Dr. May Asem Mohamed hamouda}

\section{Background and Research Problem:}

The objective of the training process is to improve the athlete to optimum performance level at his/her specific activity through integrated preparation for physical, technical, tactical, psychological, cognitive and physiological aspects. This leads the athlete to "the athletic form" in addition to improving the training process efficiency.

Sports training is a set of purposeful activities formulated according to various theories. It works on using maximum abilities, potentials and talents of the athlete is his/her specific activity to reach elite levels of performance due to his/her ability to compete and win (5: 17).

Physical preparation is an important pillar for athletic success. It mainly depends on improving general and specific physical qualities as physical fitness is the basis for all physical activities. Physical fitness plays a major role in all athletic activities. This role differs according to the type and nature of athletic activity. Each game needs a different type of physical fitness. This is called specific physical fitness (10: 84)

Physical fitness affects technical performance as athletes with high levels of physical fitness are able to use their skills and perform tactical tasks. In addition, the lack of physical fitness makes athletes more vulnerable to injuries (14: 78)

Allawy, M. (1990) indicated that physical preparation components are closely related to performing motor skills as motor skills depend on using all components of physical fitness and linking them with technical aspects (6: 194).

Shadad, M. (2010) indicated that physical preparation plays a major role in judo as its importance is increasing due to its relation to combat in dynamic and complex situations in addition to other technical aspects (11: 93)

Al-Nemr, A. \& Al-Khateeb, N. (1996) indicated that weight training is the first step towards practicing any sport as it is used to improve max strength, muscular power, endurance, tactical performance and technical performance (7: 66)

Several studies indicated the importance of weight training in improving physical and technical performance. Shadad, M. \& Mahmoud, N. (2006) indicated positive effects of weight training on entry to ground play. Abd Al-Motagaly, A. (2006) indicated positive effects of weight training on the technical performance of some defense skills during ground play. Fareed, M. (2012) indicated positive effects of specific strength exercises on the efficiency of OSAY WAZA for junior judokas (17) (1) (9).

Egyptian judo has various international and world achievements. Therefore, the main goal of judo experts is to prepare Olympic champions. Technical division of judo performance divides the game into upper play (NAGI WAZA) and lower play

\footnotetext{
${ }^{1}$ Lecturer, Combat and Individual Sports Department - Faculty of Physical Education - Tanta University
} 
(KATAMI WAZA). The most important thing during lower play is that when the judoka falls to the ground he/she modifies his/her position to lay on the abdomen so as to escape the attacker who tries to perform one of the control skills like fixation (OSAI WAZA) to finish the match. The attacker faces he problem of turning the defender on his/her back to perform fixation (OSAI WAZA) but this requires the attacker to exert effort that needs muscular strength. This led coaches to concentrate on lower or ground play skills as the judoka can finish the match through fixing, strangulating or breaking the opponent. The judoka has significant chances as an attacker to perform these skills during lower or ground play as the judoka with good lower play skills can win easily. On the other hand, a judoka who cannot attack or defense during lower play will find it difficult to achieve any results as these skills are hard to perform during upper play due to the lack of control over the opponent.

Several judo champions master the ground play (fixing, strangulating or breaking). This indicates the importance of ground play as $70 \%$ of advanced ranks came through this type of play. Most positive results also come through this type of play as the new amendments of judo rules modified the timing of ground play from $30 \mathrm{sec}$ to 25 sec to score a full point and from $25 \mathrm{sec}$ to $20 \mathrm{sec}$ to score a WAZARI. These amendments encouraged coaches to train judokas on ground play as the chance of winning through this type of play is greater (19: 90).

According to these points in addition to the field experience of the researcher it is concluded that mastering judo skills, especially ground play requires physical abilities to enable the judoka to continue ground play and control the opponent. This should be consistent with new amendments of judo rules through modifying training to increase the attacker's ability to control the opponent during ground play so as to win the match. Mere repetition of these skills will not improve them. Therefore, specific physical preparation for these skills is required through weight training. This led the researcher to try to identify the effects of specific physical preparation with weights on the performance level of ground play and controlling the opponent in judo.

\section{Aims:}

The current research aims to design specific exercises program with weight for improving muscular strength of the working muscles during ground play and controlling the opponent in addition to:

- Identifying the effects of the recommended exercises on improving explosive power of judokas

- Identifying the effects of the recommended exercises on improving the technical performance of controlling the opponent (fixing, strangulating or breaking)

\section{Hypotheses:}

1. There are statistically significant differences between the pre- and postmeasurements of the explosive power of judokas in favor of the postmeasurements

2. There are statistically significant differences between the pre- and postmeasurements of technical performance of controlling the opponent (fixing, strangulating or breaking) of judokas in favor of the post-measurements

\section{Materials and Methods:}


Approach:

The researcher used the experimental approach (one-group design) with pre- and post-measurements.

Participants:

The researcher purposefully chose (18) judokas from Ghazl Al-Mahalla Sports Clubs. Two judokas were excluded due to non-punctuality and this makes the main sample only (16) judokas. Another (12) judokas from the same research community and outside the main sample were chosen as a pilot sample. All judokas were registered at the Egyptian Federation of Judo.

Table (1): Descriptive data of participants (growth factors) $(n=16)$

\begin{tabular}{c|c|c|c|c|c|c}
\hline Variables & Measurement & Mean & Median & SD & Flatness & Squewness \\
\hline Age & Year/month & 20.38 & 20 & 0.89 & -0.16 & 0.43 \\
\hline Height & $\mathrm{Cm}$ & 172 & 172.5 & 3.20 & -1.07 & 0.11 \\
\hline Weight & $\mathrm{Kg}$ & 75.06 & 76.00 & 4.78 & 0.14 & -1.10 \\
\hline Training period & Year/month & 8.13 & 8.00 & 1.36 & 0.04 & 0.29 \\
\hline
\end{tabular}

Table (1) indicated that squewness and flatness values on all growth factors were between \pm 3 . This indicates that all data is free of radical distributions 
Table (2): Descriptive data of participants (strength tests) $(n=16)$

\begin{tabular}{c|c|c|c|c|c|c}
\hline Variables & Measurement & Mean & Median & SD & Flatness & Squewness \\
\hline Wrest flexion & $\mathrm{kg}$ & 57.13 & 57.00 & 1.31 & -0.85 & 0.06 \\
\hline $\begin{array}{c}\text { Arm flexion with } \\
\text { weight }\end{array}$ & $\mathrm{kg}$ & 60.75 & 61.00 & 1.29 & -0.64 & -0.32 \\
\hline $\begin{array}{c}\text { Arm extension with } \\
\text { weigh up }\end{array}$ & $\mathrm{kg}$ & 54.06 & 54.00 & 1.48 & -1.31 & 0.02 \\
\hline Arm raise with weight & $\mathrm{kg}$ & 73.75 & 73.50 & 1.57 & -1.55 & 0.24 \\
\hline Chest push & $\mathrm{kg}$ & 95.94 & 96.00 & 1.48 & -1.31 & -0.02 \\
\hline $\begin{array}{c}\text { Sitting from backward } \\
\text { arc }\end{array}$ & $\mathrm{kg}$ & 18.19 & 18.00 & 1.33 & -0.95 & 0.20 \\
\hline Bent rowing forward & $\mathrm{kg}$ & 104.00 & 104.00 & 1.41 & -1.17 & 0.00 \\
\hline $\begin{array}{c}\text { Low back muscle } \\
\text { extension }\end{array}$ & $\mathrm{kg}$ & 127.31 & 127.50 & 1.40 & -1.14 & -0.31 \\
\hline Half squat & $\mathrm{kg}$ & 137.06 & 137.00 & 1.34 & -1.06 & 0.06 \\
\hline Heels up & $\mathrm{kg}$ & 83.06 & 83.00 & 1.44 & -1.29 & 0.12 \\
\hline
\end{tabular}

Table (2) indicated that squewness and flatness values on all strength tests were between \pm 3 . This indicates that all data is free of radical distributions.

Table (3): Descriptive data of participants (technical tests) $(n=16)$

\begin{tabular}{c|c|c|c|c|c|c}
\hline Variables & Measurement & Mean & Median & SD & Flatness & Squewness \\
\hline Negative defender & point & 3.66 & 3.50 & 0.57 & -1.33 & 0.22 \\
\hline Positive defender & point & 3.31 & 3.50 & 0.60 & -1.52 & -0.21 \\
\hline
\end{tabular}

Table (3) indicated that squewness and flatness values on all technical tests were between \pm 3 . This indicates that all data is free of radical distributions.

Data collection tools:

\section{strength tests:}

According to experts' opinions (with $95 \%$ of agreement) the researcher identified 1RM for each of the following (10) physical tests: Wrest flexion - Arm flexion with weight - Arm extension with weigh up - Arm raise with weight - Chest push - Sitting from backward arc - Bent rowing forward - Low back muscle extension Half squat - Heels up.

\section{Technical tests:}

According to opinions of three judo judges (via a technical evaluation form) the researcher chose two technical tests:

1. Technical performance of ground play for negative judoka

2. Technical performance of ground play for positive judoka

Pilot study:

The researcher applied the physical and technical tests on a pilot sample $(n=12)$ from the same research community and outside the main sample to calculate reliability and validity of these tests. Results of this pilot study indicated that:

- All tools and equipment used in this research are valid and safe.

- Participants understand test procedures well

- Tests are valid and reliable. 
Validity of tests:

The researcher calculated distinctive validity through two equivalent groups $(\mathrm{n} 1=\mathrm{n} 2=6)$. One of these groups is the distinct (high level) group and the other is nondistinct (normal) group.

Table (4): difference significance between the distinct and non-distinct groups as an indicator for validity of strength tests $(\mathrm{n} 1=\mathrm{n} 2=6)$

\begin{tabular}{|c|c|c|c|c|c|c|c|c|}
\hline \multirow{2}{*}{ Test } & \multicolumn{2}{|c|}{ Distinct } & \multicolumn{2}{|c|}{ Non-distinct } & \multirow{2}{*}{$\begin{array}{c}\text { Difference } \\
\text { significance }\end{array}$} & \multirow{2}{*}{$\left(t^{*}\right)$} & \multirow{2}{*}{ ETA $^{2}$} & \multirow{2}{*}{ Validity } \\
\hline & Mean & SD & Mean & SD & & & & \\
\hline Wrest flexion & 57.50 & 1.05 & 48.33 & 2.94 & 9.17 & 7.18 & 0.91 & 0.95 \\
\hline $\begin{array}{l}\text { Arm flexion with } \\
\text { weight }\end{array}$ & 60.67 & 1.03 & 52.33 & 3.20 & 8.33 & 6.06 & 0.88 & 0.94 \\
\hline $\begin{array}{l}\text { Arm extension with } \\
\text { weigh up }\end{array}$ & 53.83 & 1.47 & 47.17 & 0.98 & 6.67 & 9.23 & 0.94 & 0.97 \\
\hline $\begin{array}{l}\text { Arm raise with } \\
\text { weight }\end{array}$ & 74.00 & 1.41 & 65.17 & 0.75 & 8.83 & 13.51 & 0.97 & 0.99 \\
\hline Chest push & 96.00 & 1.41 & 84.17 & 1.47 & 11.83 & 14.20 & 0.98 & 0.99 \\
\hline $\begin{array}{ll}\text { Sitting } & \text { from } \\
\text { backward arc } & \end{array}$ & 18.33 & 1.63 & 9.17 & 0.75 & 9.17 & 12.49 & 0.97 & 0.98 \\
\hline Bent rowing forward & 104.50 & 1.05 & 96.67 & 1.63 & 7.83 & 9.89 & 0.95 & 0.97 \\
\hline $\begin{array}{l}\text { Low back muscle } \\
\text { extension }\end{array}$ & 127.00 & 1.21 & 116.50 & 2.26 & 11.17 & 10.67 & 0.96 & 0.98 \\
\hline Half squat & 137.00 & 1.41 & 124.83 & 3.54 & 12.17 & 7.81 & 0.92 & 0.96 \\
\hline Heels up & 83.33 & 1.63 & 74.67 & 1.03 & 8.67 & 10.99 & 0.96 & 0.98 \\
\hline
\end{tabular}

(t) Table value on $P \leq 0.05=1.81$

Effect size for ETA2: 0: $0.30=$ weak $-0.30: 0.50=$ moderate $-\geq 0.50=$ strong

Table (4) indicated statistically significant differences between the distinct and non-distinct groups on all strength tests. In addition, the effect size and validity values are high. This proves the validity of these tests.

Table (5): difference significance between the distinct and non-distinct groups as an indicator for validity of technical tests $(n 1=n 2=6)$

\begin{tabular}{|c|c|c|c|c|c|c|c|c|}
\hline \multirow{2}{*}{ Test } & \multicolumn{2}{|c|}{ Distinct } & \multicolumn{2}{|c|}{ Non-distinct } & \multirow{2}{*}{ Difference significance } & \multirow[b]{2}{*}{ (t) } & \multirow{2}{*}{$\mathbf{E T A}^{2}$} & \multirow{2}{*}{ Validity } \\
\hline & Mean & SD & Mean & SD & & & & \\
\hline Negative defender & 4.00 & 0.44 & 2.16 & 0.26 & 1.84 & 8.70 & 0.93 & 0.96 \\
\hline Positive defender & 3.00 & 0.32 & 1.17 & 0.37 & 1.83 & 8.83 & 0.94 & 0.97 \\
\hline
\end{tabular}

Effect size for ETA2: 0: $0.30=$ weak $-0.30: 0.50=$ moderate $-\geq 0.50=$ strong

Table (5) indicated statistically significant differences between the distinct and non-distinct groups on all technical tests. In addition, the effect size and validity values are high. This proves the validity of these tests.

\section{Reliability of tests:}

The researcher calculated reliability of tests using test/retest procedures through applying tests to a pilot sample $(\mathrm{n}=12)$ from the same research community and outside the main sample with time interval of (72) hours between test and retest. 
Table (6): correlation coefficient between test and retest for strength tests $(n=12)$

\begin{tabular}{l|c|c|c|c|c}
\hline \multirow{2}{*}{\multicolumn{1}{c|}{ Test }} & \multicolumn{2}{c|}{ Test } & \multicolumn{2}{c|}{ Retest } & \multirow{2}{*}{$(\mathbf{R})$} \\
\cline { 2 - 5 } & Mean & SD & Mean & SD & \\
\hline Wrest flexion & 52.92 & 3.84 & 53.58 & 2.19 & 0.86 \\
\hline Arm flexion with weight & 56.50 & 4.17 & 58.00 & 3.38 & 0.84 \\
\hline Arm extension with weigh up & 50.50 & 2.03 & 51.33 & 1.88 & 0.90 \\
\hline Arm raise with weight & 69.59 & 2.49 & 70.12 & 3.46 & 0.88 \\
\hline Chest push & 90.09 & 2.11 & 91.47 & 3.82 & 0.89 \\
\hline Sitting from backward arc & 13.75 & 1.94 & 14.10 & 1.67 & 0.92 \\
\hline Bent rowing forward & 100.59 & 2.17 & 102.16 & 2.31 & 0.85 \\
\hline Low back muscle extension & 122.09 & 3.25 & 123.00 & 3.16 & 0.87 \\
\hline Half squat & 130.92 & 4.51 & 132.42 & 2.29 & 0.86 \\
\hline Heels up & 79.00 & 2.75 & 79.68 & 3.86 & 0.84 \\
\hline
\end{tabular}

(R) Table value on $P \leq 0.05=0.57$

Table (6) indicated statistically significant correlations between test and retest. This indicates the reliability of strength tests.

Table (7): correlation coefficient between test and retest for technical tests $(n=12)$

\begin{tabular}{c|c|c|c|c|c}
\hline \multirow{2}{*}{ Test } & \multicolumn{2}{|c|}{ Test } & \multicolumn{2}{c|}{ Retest } & \multirow{2}{*}{$(\mathbf{R})$} \\
\cline { 2 - 6 } & Mean & SD & Mean & SD & \\
\hline Negative defender & 3.08 & 0.73 & 3.16 & 0.61 & 0.91 \\
\hline Positive defender & 2.09 & 0.56 & 2.14 & 0.47 & 0.93 \\
\hline
\end{tabular}

(R) Table value on $P \leq 0.05=0.57$

Table (7) indicated statistically significant correlations between test and retest. This indicates the reliability of technical tests.

\section{Specific exercises used in the program:}

The main objectives of these exercises are:

- To improve the maximum muscular strength of first class judokas

- To improve the technical performance level of ground play skills during the program

The program included (12) weeks (3 units per week) with total number of (36) training units.

\section{The program principles:}

1. The researcher depended on individual loading principle through identifying the $\max$ load (1RM) for each exercise and then determining the suitable intensity and volume.

2. Load intensity is increased gradually through weight, team mate weight, rest intervals, resistances and training duration.

3. The researcher used various exercises so that each exercises is different from the one preceding it

4. Max improvement for muscular strength is set according to the requirements of technical skill to be improved.

5. Program content is suitable for judokas' abilities

6. The program considers individual differences among judokas

7. The program is consistent with its objectives. 
Ordering of exercises:

Al-Nemr, A. \& Al-Khateeb, N. (1996) indicated that when improving max muscular strength we should start with major group exercises like squats and pulls for the following reasons:

1. Major muscles use the heaviest weights and are of major importance for improving strength

2. Major muscles consume relatively large amounts of energy and cause general and local muscular fatigue

3. Due to the large amount of energy consumed by these larger muscles, it is advised to train lesser muscles with relatively low energy consumption at the end of a training unit as an effective cool down (14: 223).

\section{Tools and equipment:}

Judo mat - stop watch - medical balance - figures with various weights - various weight (bars and bells 10:20 kg) - sand bags with various weights - medicine balls with various weights - rubber cords - benches - data recording forms

\section{Pre-measurements:}

The researcher took pre-measurements for all strength and technical variables through identified tests

Main application:

The recommended specific weight exercises program took (12) weeks ( 3 units per week). Non-punctual judokas were excluded.

Post-measurements:

The researcher applied and technical tests in post-measurements following the same protocol as pre-measurements.

\section{Statistical treatment:}

The researcher used SPSS software to calculate the following: mean - median $\mathrm{SD}$ - flatness - squewness - (t) test - improvement percentage - ETA2 - effect size according to Cohen's equation. 
- 8 -

Distribution of exercises and intensities over training weeks

\begin{tabular}{|c|c|c|c|c|c|c|c|c|c|c|c|c|c|}
\hline days & $\begin{array}{c}\text { weeks } \\
\text { components }\end{array}$ & 1 & 2 & 3 & 4 & 5 & 6 & 7 & 8 & 9 & 10 & 11 & 12 \\
\hline & Weights & $1-3-5-7-9$ & $\begin{array}{c}12-14-16- \\
18-20\end{array}$ & $2-4-6-8-10$ & $\begin{array}{c}11-13-15- \\
17-19\end{array}$ & $1-3-5-7-9$ & $\begin{array}{c}11-13-15- \\
17-19\end{array}$ & \begin{tabular}{|c|}
$12-14-16-$ \\
$18-20$
\end{tabular} & \begin{tabular}{|c|}
$22-24-26-$ \\
$28-30$
\end{tabular} & \begin{tabular}{|c}
$22-24-26-$ \\
$28-30$
\end{tabular} & \begin{tabular}{|c|}
$21-23-25-$ \\
$27-29$
\end{tabular} & $1-3-5-7-9$ & $\begin{array}{c}12-14-16- \\
18-20 \\
\end{array}$ \\
\hline & Skill & Ex 1 & Ex 2 & Ex 3 & Ex 4 & Ex 5 & Ex 6 & Ex 7 & Ex 8 & Ex 9 & Ex 10 & Ex 11 & Ex 12 \\
\hline & Intensity & $65 \%$ & $75 \%$ & $75 \%$ & $85 \%$ & $85 \%$ & $90 \%$ & $95 \%$ & $90 \%$ & $85 \%$ & $85 \%$ & $80 \%$ & $70 \%$ \\
\hline & Weights & $2-4-6-8-10$ & \begin{tabular}{|c|}
$21-23-25-$ \\
$27-29$ \\
\end{tabular} & $1-3-5-7-9$ & $\begin{array}{c}21-23-25- \\
27-29 \\
\end{array}$ & $2-4-6-8-10$ & \begin{tabular}{|c|}
$21-23-25-$ \\
$27-29$ \\
\end{tabular} & $1-3-5-7-9$ & $\begin{array}{c}11-13-15- \\
17-19 \\
\end{array}$ & $1-3-5-7-9$ & $2-4-6-8-10$ & $2-4-6-8-10$ & $\begin{array}{c}21-23-25- \\
27-29 \\
\end{array}$ \\
\hline & Skill & Ex 1 & Ex 2 & Ex 3 & Ex 4 & Ex 5 & Ex 6 & Ex 7 & Ex 8 & Ex 9 & Ex 10 & Ex 11 & Ex 12 \\
\hline & Intensity & $65 \%$ & $75 \%$ & $75 \%$ & $85 \%$ & $85 \%$ & $90 \%$ & $95 \%$ & $90 \%$ & $85 \%$ & $85 \%$ & $80 \%$ & $70 \%$ \\
\hline & Weights & $\begin{array}{c}11-13-15- \\
17-19 \\
\end{array}$ & $\begin{array}{c}22-24-26- \\
28-30 \\
\end{array}$ & \begin{tabular}{|c|}
$12-14-16-$ \\
$18-20$ \\
\end{tabular} & \begin{tabular}{|c|}
$22-24-26-$ \\
$28-30$ \\
\end{tabular} & \begin{tabular}{|c|}
$12-14-16-$ \\
$18-20$ \\
\end{tabular} & \begin{tabular}{|c|}
$22-24-26-$ \\
$28-30$ \\
\end{tabular} & $2-4-6-8-10$ & $\begin{array}{c}21-23-25- \\
27-29 \\
\end{array}$ & \begin{tabular}{|c|}
$11-13-15-$ \\
$17-19$ \\
\end{tabular} & \begin{tabular}{|c|}
$12-14-16-$ \\
$18-20$ \\
\end{tabular} & \begin{tabular}{|c|}
$11-13-15-$ \\
$17-19$ \\
\end{tabular} & $\begin{array}{c}22-24-26- \\
28-30 \\
\end{array}$ \\
\hline & Skill & Ex 1 & Ex 2 & Ex 3 & Ex 4 & Ex 5 & Ex 6 & Ex 7 & Ex 8 & Ex 9 & Ex 10 & Ex 11 & Ex 12 \\
\hline & Intensity & $65 \%$ & $75 \%$ & $75 \%$ & $85 \%$ & $85 \%$ & $90 \%$ & $95 \%$ & $90 \%$ & $85 \%$ & $85 \%$ & $80 \%$ & $70 \%$ \\
\hline & $\begin{array}{c}\text { Warm up for all } \\
\text { units }\end{array}$ & \multicolumn{12}{|c|}{ Running forward and sideward with swings and general stretches and specific stretches for working muscles } \\
\hline & $\begin{array}{c}\text { Cool down for all } \\
\text { units }\end{array}$ & & & & & & & & 1 & & & & \\
\hline
\end{tabular}




\section{Results:}

Table (8): Difference significance between the pre- and post-measurements of the researcher group on strength tests $(n=16)$

\begin{tabular}{|c|c|c|c|c|c|c|c|c|c|}
\hline \multirow{2}{*}{ Test } & \multicolumn{2}{|c|}{ Pre- } & \multicolumn{2}{|c|}{ Post- } & \multirow{2}{*}{$\begin{array}{c}\text { Difference } \\
\text { significance }\end{array}$} & \multirow{2}{*}{$\begin{array}{l}\text { Standard } \\
\text { error }\end{array}$} & \multirow{2}{*}{$\left(\mathrm{T}^{*}\right)$} & \multirow[b]{2}{*}{ Significance } & \multirow{2}{*}{$\begin{array}{c}\text { Improvement } \\
\text { percentage } \\
(\%)\end{array}$} \\
\hline & Mean & SD & Mean & SD & & & & & \\
\hline $\begin{array}{l}\text { Wrest } \\
\text { flexion }\end{array}$ & 57.13 & 1.31 & 71.94 & 1.44 & 14.81 & 1.32 & 11.22 & 0.00 & 25.93 \\
\hline $\begin{array}{l}\text { Arm } \\
\text { flexion } \\
\text { with } \\
\text { weight }\end{array}$ & 60.75 & 1.29 & 72.88 & 1.41 & 12.13 & 1.14 & 10.64 & 0.00 & 19.96 \\
\hline $\begin{array}{l}\text { Arm } \\
\text { extension } \\
\text { with } \\
\text { weigh up }\end{array}$ & 54.06 & 1.48 & 64.63 & 1.45 & 10.56 & 1.03 & 10.25 & 0.00 & 19.54 \\
\hline $\begin{array}{l}\text { Arm raise } \\
\text { with } \\
\text { weight }\end{array}$ & 73.75 & 1.57 & 85.06 & 1.44 & 11.31 & 1.220 & 9.27 & 0.00 & 15.34 \\
\hline $\begin{array}{l}\text { Chest } \\
\text { push }\end{array}$ & 95.94 & 1.48 & 116.13 & 1.50 & 20.19 & 1.640 & 12.31 & 0.00 & 21.77 \\
\hline $\begin{array}{l}\text { Sitting } \\
\text { from } \\
\text { backward } \\
\text { arc }\end{array}$ & 18.19 & 1.33 & 22.88 & 1.50 & 4.69 & 0.390 & 12.02 & 0.00 & 25.77 \\
\hline $\begin{array}{l}\text { Bent } \\
\text { rowing } \\
\text { forward }\end{array}$ & 104.00 & 1.41 & 117.06 & 1.34 & 13.06 & 1.58 & 8.27 & 0.00 & 12.56 \\
\hline $\begin{array}{l}\text { Low back } \\
\text { muscle } \\
\text { extension }\end{array}$ & 127.31 & 1.40 & 144.94 & 1.48 & 17.63 & 1.84 & 9.58 & 0.00 & 13.84 \\
\hline Half squat & 137.06 & 1.34 & 154.06 & 1.44 & 17.00 & 1.91 & 8.90 & 0.00 & 12.40 \\
\hline Heels up & 83.06 & 1.44 & 100.19 & 1.42 & 17.13 & 1.49 & 11.49 & 0.00 & 20.62 \\
\hline
\end{tabular}

(T) Table value on $P \leq 0.05=1.75$

Table (8) indicates statistically significant differences between pre- and postmeasurements of the strength tests as $(\mathrm{T})$ calculated value $(8.27: 12.31)$ was higher than its table value and improvement percentages ranged from 12.56 to 25.93 .

Table (9): Effect size according to Cohen's equation for strength tests $(n=16)$

\begin{tabular}{l|c|c|c|c|c}
\hline \multicolumn{1}{c|}{ Test } & $(\mathbf{T})$ & Significance & \multirow{2}{*}{ ETA $^{\mathbf{2}}$} & Effect size & \multirow{2}{*}{ Significance } \\
\hline Wrest flexion & 11.22 & 0.00 & 0.89 & 3.70 & High \\
\hline Arm flexion with weight & 10.64 & 0.00 & 0.88 & 3.40 & High \\
\hline Arm extension with weigh up & 10.25 & 0.00 & 0.87 & 3.08 & High \\
\hline Arm raise with weight & 9.27 & 0.00 & 0.84 & 2.97 & High \\
\hline Chest push & 12.31 & 0.00 & 0.90 & 3.08 & High \\
\hline Sitting from backward arc & 12.02 & 0.00 & 0.90 & 3.85 & High \\
\hline Bent rowing forward & 8.27 & 0.00 & 0.81 & 2.73 & High \\
\hline Low back muscle extension & 9.58 & 0.00 & 0.85 & 3.07 & High \\
\hline Half squat & 8.90 & 0.00 & 0.83 & 2.94 & High \\
\hline Heels up & 11.49 & 0.00 & 0.89 & 2.87 & High \\
\hline
\end{tabular}

Effects size: $0.20=$ low $-0.50=$ moderate $-0.80=$ high

Tables (8) and (9) indicated that (T) calculated value (8.27: 12.31) was higher than its table value and improvement percentages ranged from 12.56 to 25.93. In addition, the effect size for all tests was high.

Therefore, we can say that the recommended training program led to improvements in strength variables due to its positive effects. 
The researcher thinks that the main objective of weight training is to improve the performance level of an athlete to its maximum level so as to be able to win in major championships. Athletes improve their muscular strength and other physical abilities through training. Weight training is the optimum method for improving physical abilities and muscular strength as it improves the performance level of an athlete. Weight training programs can be used in various sports as it is easy to control resistances (8: 38).

Judo is a sport where judokas exert major physical effort during combat. Therefore, a judoka should have specific physical abilities to enable him/her to compete effectively. Isao Nabuyuji (1991) and Kleine Emzy (1980) indicated that judokas need specific physical abilities to achieve optimum performance (20:31) (1: 147).

Table (10): Difference significance between the pre- and post-measurements of the researcher group on technical tests $(n=16)$

\begin{tabular}{c|c|c|c|c|c|c|c|c|c}
\hline \multirow{2}{*}{ Test } & \multicolumn{2}{|c|}{ Pre- } & \multicolumn{2}{c|}{ Post- } & $\begin{array}{c}\text { Difference } \\
\text { significance }\end{array}$ & $\begin{array}{c}\text { Standard } \\
\text { error }\end{array}$ & (T) & Significance & $\begin{array}{c}\text { Improvement } \\
\text { percentage } \\
(\%)\end{array}$ \\
\hline $\begin{array}{c}\text { Negative } \\
\text { defender }\end{array}$ & 3.66 & 0.57 & 6.97 & 0.69 & 3.31 & 0.232 & 14.27 & 0.00 & 90.60 \\
\hline $\begin{array}{c}\text { Positive } \\
\text { defender }\end{array}$ & 3.31 & 0.60 & 6.41 & 0.58 & 3.09 & 0.195 & 15.88 & 0.00 & 93.40 \\
\hline
\end{tabular}

(T) Table value on $P \leq 0.05=1.75$

Table (10) indicates statistically significant differences between pre- and postmeasurements of the technical tests as $(\mathrm{T})$ calculated value (14.27: 15.88) was higher than its table value and improvement percentages ranged from 90.60 to 93.40.

Table (11): Effect size according to Cohen's equation for tests tests $(n=16)$

\begin{tabular}{c|c|c|c|c|c}
\hline Test & $(\mathbf{T})$ & Significance & ETA $^{\mathbf{2}}$ & Effect size & Significance \\
\hline Negative defender & 14.27 & 0.00 & 0.93 & 4.99 & High \\
\hline Positive defender & 15.88 & 0.00 & 0.94 & 5.40 & High \\
\hline
\end{tabular}

Effects size: $0.20=$ low $-0.50=$ moderate $-0.80=$ high

Tables (10) and (11) indicated that (T) calculated value (14.27: 15.88) was higher than its table value and improvement percentages ranged from 90.60 to 93.40. In addition, the effect size for all tests was high.

The researcher thinks that the recommended training program improved technical performance level of the research group in ground play skills due to its positive effects. Therefore, we can say that improving muscular strength of the working muscles for judo has positive effects on technical performance of ground play skills (fixing, strangulating or breaking).

These results indicate that the recommended program had positive effects on physical and technical variables under investigation. This is consistent with Mosaad Ali (1988), Hamdy Nour El-Din (1992), Hatem Yousef (1992), Tarek Abd El-Raouf (1993), Ali Raihan (1994), Wageeh Shamandy (1995), Hamdy Baghdady (1999) and Mohamed Al-Gammal (2007) (8) (16) (5) (10) (2) (12) (4) (15).

Studies about weight training and other training aids indicated the positive effects of this type of training on improving specific physical abilities required for the specific sports activity. 
Fixing, strangulating or breaking are favorable techniques for judokas during ground play as they can apply them while the opponent is on his back or on his belly to win the match. These techniques make ground play more effective than upper play as in this case the judoka takes full control over his/her opponent who is on the mat and who is more vulnerable to attack and loss (21: 97).

Mohamed Shaddad (2001) thinks that ground play skills including fixing, strangulating and breaking are the weapons a judoka uses to control the opponent and win the match. These skills link tactics to other physical, technical and psychological aspects of judoka preparation for competition (22: 20).

\section{Conclusions:}

1. The recommended training program improved muscular strength and technical performance level of ground play for all participants.

2. There are statistically significant differences between pre- and postmeasurements of muscular strength in favor of post-measurements as improvement values were (25.93\%: $12.40 \%)$.

3. There are statistically significant differences between pre- and postmeasurements of technical performance of ground play in favor of postmeasurements as improvement values were (90.60\%) for negative judoka and (93.40\%) for positive judoka.

\section{Recommendations:}

In the light of these results, the researcher recommends the following:

1. Period of the weight training programs should not be less than (8) weeks

2. The recommended training program should be applied to all judo teams under supervision of the Egyptian Federation of Judo

3. It is important to carefully design weight training programs for improving muscular strength of judokas in addition to identifying their weaknesses to improve it as a step towards improving their technical performance.

4. Stretches and flexibility exercises with modern tools should be part of weight training programs

5. Follow up and continuous evaluation should be considered all along the program application.

\section{References:}

1- Abd El-Motagally, Atef (2006): Effects of a recommended training program on improving some defense moves for ground [lay in Judo. Master thesis, Faculty of Physical Education- Al-Mansoura University - Egypt (in Arabic)

2- Abd El-Raouf, Tarek M. (1993): Effects of specific weight exercises on some physical fitness components in basketball. Master thesis, Faculty of Physical Education for Men- Helwan University - Egypt (in Arabic)

3- Abd El-Razek, Medhat Kasem (2004): Health clubs (health and fitness - weight loss - body building). Dar Al-Fikr Al-Araby - Cairo - Egypt (in Arabic)

4- Al-Gebaly, Mohamed I. (2007): A recommended training program for improving the opposite waist snatch in Greco-Roman Wrestling. Master thesis, Faculty of Physical Education for Men - Helwan University - Egypt (in Arabic)

5- Al-Gebaly, Owais (2003): Sports Training (theory and Practice). Dar Al-Fikr AlAraby - Cairo - Egypt (in Arabic) 
6- Allawy, Mohamed Hassan (1990): Sports Training, $2^{\text {nd }}$ ED. Dar Al-Maaref Cairo - Egypt (in Arabic)

7- Al-Nemr, A. \& Al-Khateeb, N. (1996): Weight training: designing strength programs and planning the training season. Markaz Al-Ketab Press, $1^{\text {st }}$ ED. Cairo - Egypt (in Arabic)

8- Baghdady, Hamdy A. (1999): Effects of recommended training program on the technical performance of twist and opposite waist snatch for junior wrestlers. Master thesis, Faculty of Physical Education for Men- Helwan University Egypt (in Arabic)

9- $\quad$ Fareed, Mona Taha (2012): Effects of some specific exercises on the performance level of some OSAY WAZA skills for junior judokas less than 13 years. Master thesis, Faculty of Physical Education- Al-Mansoura University - Egypt (in Arabic)

10- Hasanain, Mohamed Sobhy (1988): Encyclopedia of Sports Training, $1^{\text {st }}$ ED Markaz Al-Ketab Press - Cairo - Egypt (in Arabic)

11- Isao , Inokuma (1991): Best judo .3th ED, published by kodansha International 1 td , Japan

12- Kleine ,Emzy (1980): Korper kultur and sports. Ev13, biliographisches, Institute , Leipzig

13- Mahmoud, Mosaad Ali (1988): Theory and Practice for Greco-Roman and Free Wrestling. Al-Amal Press - Zagazig - Egypt (in Arabic)

14- Noaman, A. \& Saleh, M. (2000): Soccer (training and tactics). Dar Al-Fikr AlAraby - Cairo - Egypt (in Arabic)

15- Nour El-Din, Hamdy (1992): Effects of a recommended training program for improving arms and legs muscular power on the technical performance of some basic skills for junior volleyball players less than 16 years. Master thesis, Faculty of Physical Education at Port Said-Suez Canal University - Egypt (in Arabic)

16- Raihan, Ali Al-Said (1994): Effects of specific weight exercises on the effectiveness of technical performance for wrestlers. The Scientific Conference of Faculty of Physical Education for Men - Helwan University - Egypt (in Arabic)

17- Shaddad, Mohamed H. \& Mahmoud, Nivin H. (2006): Effects of a recommended training program for improving muscular power on the performance level of some ground play entries in judo. Scientific Journal of Faculty of Physical EducationZagazig University - Egypt (in Arabic)

18- Shaddad, Mohamed H. (2010: Modern Methods of Teaching Judo, $1^{\text {st }}$ ED. Shams Press - Cairo - Egypt (in Arabic)

19- Shaddad, Mohamed H. (2015): Technique in Judo. Shams Press - Cairo - Egypt (in Arabic)

20- Shamandy, Wageeh A. (1995): Effects of a recommended training program for improving some specific motor abilities on the effectiveness of technical and tactical performance for wrestlers. Scientific Journal of Physical Education and Sport, Faculty of Physical Education for Men - Helwan University, No. 23. Egypt (in Arabic)

21- Yamamoto (2001): Judo Training. The Egyptian Federation of Judo - Egypt (in Arabic)

22- Yousef, Hatem H. (1992): Effects of a recommended training program with weights during the preparation phase on the digital record of the Egyptian national team's swimmers. Master thesis, Faculty of Physical Education for Women- Helwan University - Egypt (in Arabic) 